\title{
Komunikasi Interpersonal dan Kepuasan Pernikahan pada Partner Phubbing
}

\section{Interpersonal Communication and Marital Satisfaction in Partner Phubbing}

\author{
Ayu Purnamasari, Amalia Juniarly, Lily Paradita \\ Program Studi Psikologi Fakultas Kedokteran Universitas Sriwijaya \\ Email: ayupurnamasari@fk.unsri.ac.id; amaliajuniarly@fk.unsri.ac.id; lily120218@gmail.com
}

\begin{abstract}
KATA KUNCI Kepuasan Pernikahan, Komunikasi Interpersonal, Partner Phubbing.

KEYWORDS Interpersonal Communication, Marital Satisfaction, Partner Phubbing.
\end{abstract}

ABSTRAK Penelitian ini bertujuan untuk mengetahui peran komunikasi interpersonal terhadap kepuasan pernikahan pada partner phubbing. Hipotesis dari penelitian ini adalah terdapat peran komunikasi interpersonal terhadap kepuasan pernikahan pada partner phubbing. Partisipan pada penelitian ini adalah 286 individu yang telah menikah dan memiliki pasangan pengguna gadget, ada sebanyak 230 orang yang dipilih sebagai subjek penelitian karena berada dalam kategori partner phubbing sedang dan tinggi. Penelitian ini menggunakan satu buah kuesioner dan dua buah skala sebagai alat ukur, yakni kuisioner partner phubbing yang digunakan untuk menyeleksi subjek penelitian, skala kepuasan pernikahan, dan skala komunikasi interpersonal. Data dianalisis dengan analisis regresi sederhana. Hasil penelitian menunjukkan ada peran komunikasi interpersonal dan kepuasan pernikahan pada partner phubbing dengan nilai $\mathrm{R}$ square $=0,434$ dan $\mathrm{p}$ $=0,000(\mathrm{p}<0,05)$. Komunikasi interpersonal memiliki peran dalam menentukan kepuasan pernikahan pada partner phubbing. Oleh sebab itu, hipotesis dalam penelitian ini dapat diterima.

ABSTRACT This study aims to determine the role of interpersonal communication on marital satisfaction in partner phubbing. The hypothesis of this research is the role of interpersonal communication on marital satisfaction in partner phubbing. Participants in this study were 286 individuals who were married and had a pair of gadget users. There were 230 people were selected as research subjects because they were in the category of medium and high partner phubbing. This study uses one questionnaire and two scales as a measuring instrument, namely the partner phubbing questionnaire utilized to select research subjects, marital satisfaction scale, and interpersonal communication scale. Data were analyzed by simple regression analysis. The results showed there was a role of interpersonal communication on marital satisfaction in partner 
phubbing with $R$ square $=0.434$ and $p=0,000$ ( $p<0.05)$. Interpersonal communication has a role in determining marital satisfaction with partner phubbing. Therefore, the hypothesis in this study can be accepted.

\section{PENDAHULUAN}

Pertumbuhan model komunikasi sulit terhindarkan akibat dari adanya pertumbuhan teknologi yang pesat seperti perbedaan bentuk interaksi antar individu yang dipengaruhi oleh keberadaan gadget (Youarti \& Hidayah, 2018). Riset dari Emarketer (2015) memprediksi banyaknya pengguna aktif gadget di Indonesia pada 2018 akan menyentuh angka melebihi dari 100 juta pengguna. Angka pengguna yang semakin meningkat, menjadikan Indonesia memiliki predikat sebagai negara dengan pengguna aktif gadget nomor empat dunia di bawah Cina, India, dan Amerika.

Pew Research Center (2018) melakukan survei terhadap 30.133 individu pada 27 negara dengan tujuan agar melihat rasio pengguna smartphone dan handphone seluler pada orang dewasa ditemukan hasil Indonesia menduduki peringkat 24 dari 27 negara. Sebanyak $42 \%$ mempunyai smartphone, $28 \%$ mempunyai handphone biasa, dan $29 \%$ tidak mempunyai handphone.

Dari berbagai kalangan dan lapisan usia saat ini sudah menjadi pengguna aktif gagdet. Pada awalnya teknologi membawa berbagai kemudahan, namun seiring berjalannya waktu justru menciptakan rasa kesepian dan menurunnya interaksi sosial secara langsung. Kemunculan internet, gadget, tv, dan komputer mengakibatkan manusia terlalu fokus dengan kehidupan di depan layar dibandingkan anggota keluarga atau bahkan pasangan mereka sendiri sehingga merenggangnya hubungan satu sama lain dan menciptakan konflik-konflik yang baru (Ngafifi, 2014).

Salah satu efek negatif dari penggunaan gadget yang berlebihan yakni meningkatkan sifat individualis dan berkurangnya interaksi secara langsung.
Mereka cenderung memilih memainkan gadget daripada berinteraksi dengan orang sekitar (Marpaung, 2018). Gadget telah menjelma sebagai kebutuhan hidup yang sulit terpisahkan bagi individu pada berbagai kalangan dan lapisan usia di berbagai negara (Chotpitayasunondh \& Douglas, 2016). Fakta yang banyak ditemui pada masa sekarang ialah adanya perilaku sibuk memainkan gadget ketika sedang bersama orang lain.

Dengan adanya kebiasaan tersebut maka muncul istilah phubbing. Phubbing terdiri dari dua kata yakni phone dan snubbing, yang merujuk pada tindakan pengabaian terhadap orang lain pada saat bersama karena pengaruh gadget (Roberts \& David, 2016). Seseorang yang melakukan tindakan tersebut terhadap pasangannya dikenal sebagai partner phubbing (phubbing). McDaniel dan Coyne (2016) mengemukakan ada $70 \%$ dari 143 wanita yang sedang terlibat dalam hubungan romantis menyatakan bahwa intensitas dalam menggunakan gadget "kadangkadang", "sering" dan "sepanjang waktu" oleh pasangan menyebabkan terganggunya interaksi dengan satu sama lain. Hasil riset juga menyatakan partner phubbing seakan menjadi lumrah untuk dilakukan pada pasangan romantis.

Survey awal dilakukan peneliti dengan tujuan ingin mengetahui ada atau tidak fenomena phubbing pada pasangan yang sudah menikah karena menurut Roberts dan David (2016), partner phubbing adalah tindakan menggunakan gadget ketika bersama pasangan. Ada sebanyak 16 subjek, enam subjek laki-laki dan 10 subjek perempuan baik pasangan ataupun subjek sama-sama memiliki gadget.

Dari survey yang dilakukan, menunjukkan ada $77,3 \%$ responden 
mengungkapkan pasangan mereka segera melihat gadget ketika notifikasi berbunyi sekalipun sedang berbincang-bincang berdua. Sebanyak $81,8 \%$ responden mengungkapkan bahwa pasangan mereka selalu menaruh gadget di tempat yang dekat dengan jangkauan misalnya di sebelah kasur, meja, dan saku. Selanjutnya, 68,2\% mengatakan bahwa ketika quality time berdua, pasangan mereka tetap aktif memainkan gadget.

Roberts dan David (2016) dalam penelitiannya mengungkapkan intensitas partner phubbing yang semakin tinggi akan berdampak pada kepuasan pasangan dalam menjalani hubungan yang semakin rendah. Adanya perilaku phubbing yang dilakukan pasangan menimbulkan permasalahan yang jelas dikarenakan oleh adanya gadget. Kemudian Wang, Zhao, dan Lei (2019) melakukan riset tentang partner phubbing di China terhadap 429 responden, yakni 243 responden sudah menikah dan 186 responden belum menjalani pernikahan. Dari riset tersebut didapatkan bahwa ada hubungan yang signifikan antara partner phubbing dengan kepuasan hubungan pada pasangan yang sudah menikah, untuk pasasangan yang belum menikah memperlihatkan hasil yang tidak signifikan. Chotpitayasunondh dan Douglas (2018) menyatakan bahwa phubbing tidak hanya berpengaruh terhadap kepuasan hubungan namun juga pada kualitas komunikasi seseorang. Hasil penelitian tersebut memperlihatkan bahwa intensitas peningkatan perilaku phubbing secara signifikan dan negatif dapat mempengaruhi kualitas komunikasi dan kepuasan hubungan. Efek ini dimediasi oleh berkurangnya perasaan memiliki dan afeksi negatif serta afeksi positif.

Carandang dan Guda (2015) menyatakan kepuasan pernikahan bisa ditentukan dari bagaimana seseorang memperlihatkan intimasi, keterikatan, rasa cinta dan gairah positif ketika mengarungi bahtera pernikahan. Puas atau tidaknya perkawinan dapat juga terlihat dari intimasi, afeksi, pemuasan seksual, kemapanan finansial, dan tumbuh kembang emosional (Papalia, Olds \& Feldman, 2009).

Macam-macam faktor yang memberikan dampak dalam kepuasan pernikahan satu diantaranya yakni hubungan interpersonal pasangan (Srisusanti \& Zulkaida, 2013). Tetapi nyatanya, akhirakhir ini ada bermacam-macam konflik yang dapat memicu rusaknya hubungan interpersonal suami istri dikarenakan pemakaian gadget. Konflik-konflik yang kerap kali timbul seperti perselingkuhan, kurangnya tanggung jawab terhadap peran dalam keluarga, dan kualitas komunikasi secara langsung karena lebih sering beinteraksi melalui media sosial melalui gadget (Iqbal, 2018).

Iqbal (2018) mengemukakan komunikasi memiliki peranan yang besar terhadap kepuasan pernikahan. Komunikasi interpersonal menurut DeVito (2010) ialah penyampaian pesan dari individu satu ke individu lain yang disertai dengan feedback langsung. Muslimah (2014) menyebutkan komunikasi interpersonal berdampak pada kepuasan pernikahan bahwa kepuasan pernikahan yakni semakin efektif komunikasi makan semakin puas perkawinan tersebut. Pernikahan yang baik perlu adanya korelasi dan tidak ada yang ditutup-tutupi satu sama lain. Komunikasi yang jujur dapat mengakhiri konflik yang ada dalam perkawinan (Iqbal, 2018).

Lavner, Karney, dan Bradbury (2016) mengutarakan jika kepuasan hubungan suami dam istri bisa dinilai dari tindakan-tindakan serta cara interaksi mereka. Komunikasi yang diperlihatkan melalui hal-hal yang positif maka akan memiliki output yang positif pula begitupun sebaliknya.

Litzinger dan Gordon (2005) dalam risetnya mendapatkan bahwa salah satu yang berperan dalam kepuasan perkawinan yakni adanya interaksi interpersonal yang efektif dengan pasangan yakni meliputi kecakapan menjadi pendengar yang baik dan kecakapan dalam mengekspresikan diri. Ketidakefektifan dalam berkomunikasi verbal ataupun non verbal dapat 
menimbulkan celah pada pernikahan yang mengakibatkan turunnya tingkat kepuasan dalam pernikahan (Tavakolizadeh, Nejatian, \& Soori, 2014).

Pada kenyataannya, di era modern seperti saat ini komunikasi dengan pasangan dapat terganggu karena adanya perilaku phubbing yang berdampak buruk dalam sebuah hubungan. Kala seseorang memilih untuk menggunakan teknologi dibandingkan menciptakan waktu yang berkualitas bersama-sama maka akan memunculkan rasa diabaikan oleh salah satu pihak. Phubbing bisa menjadi pemicu munculnya permasalahan jika salah salah satu pihak merasa dirugikan, munculnya rasa marah dan benci bukan hal yang mustahil terjadi jika menggunakan gadget selalu dianggap lumrah dilakukan padahal bisa berbahaya untuk kelangsungan hubungan dan kesehatan mental seseorang (Roberts \& David, 2016).

Berdasarkan berbagai latar belakang permasalahan yang telah dijabarkan di atas, maka dapat dilihat bahwa di era modern penggunaan gadget dapat membawa dampak negatif dalam hubungan pernikahan. Intensitas penggunaan gadget yang semakin sering dilakukan ketika sedang bersama pasangan dapat memunculkan konflik dalam kehidupan pernikahan dan memunculkan permasalahan baru yakni adanya partner phubbing yang dapat menganggu keefektifan komunikasi dengan pasangan. Oleh sebab itu, peneliti menetapkan hipotesis dalam penelitian ini yaitu terdapat peran komunikasi interpersonal terhadap kepuasan pernikahan pada partner phubbing.

\section{METODE PENELITIAN Pendekatan}

Pendekatan yang digunakan dalam penelitian ini adalah pendekatan kuantitatif.

\section{Partisipan}

Populasi dalam penelitian ini adalah individu yang telah menikah dan memiliki pasangan pengguna gadget. Adapun sampel dalam penelitian ini berjumlah 286 individu, namun yang memenuhi kriteria hanya sebanyak 230 subjek. Kriteria dalam penelitian ini adalah individu berada dalam kategori partner phubbing sedang atau tinggi dan berusia tidak lebih dari 54 tahun. Survey dalam penelitian ini disebarkan secara online dan langsung kepada subjek. Tautan survey online disebarkan melalui berbagai platform media sosial seperti Instagram, Facebook, Whatsapp, Twitter, dan Line. Subjek ditentukan menggunakan teknik purposive sampling.

Berdasarkan data yang telah dikumpulkan, diperoleh sebanyak 230 subjek. Subjek dengan kategori partner phubbing sedang sebanyak 187 orang $(81,3 \%)$ dan subjek berada dalam kategori partner phubbing tinggi sebanyak 43 orang $(18,7 \%)$. Berdasarkan jenis kelamin, diperoleh subjek perempuan sebanyak 165 orang $(71,7 \%)$ dan laki-laki sebanyak 65 orang $(28,3 \%)$. Rentang usia subjek didominasi oleh dewasa awal dengan rentang usia 26 sampai 35 tahun sebanyak 97 orang $(42,2 \%)$. Data usia pernikahan subjek paling banyak berada dalam usia pernikahan 0 sampai 3 tahun yakni berjumlah 107 orang (46,5\%). Selanjutnya, dari data jumlah anak subjek penelitian mayoritas subjek memiliki 1 anak yakni sebanyak 73 orang (31,7\%). Kemudian sebanyak 206 (89,6\%) subjek tinggal bersama dengan pasangannya dan 24 $(10,4 \%)$ subjek menjalani long distance Marriage. Subjek didominasi oleh ibu rumah tangga, yakni sebanyak 33,5\%.

\section{Instrumen}

Penelitian ini menggunakan dua skala psikologi dan satu kuesioner yakni untuk mengukur kepuasan pernikahan, komunikasi interpersonal dan partner phubbing. Skala kepuasan pernikahan mengacu pada aspek-aspek kepuasan pernikahan yang dibuat oleh Bradbury, Fincham, dan Beach (2000) yakni kognisi, afeksi, fisiologis, pola interaksi, dukungan sosial dan kekerasan yang terdiri dari 18 aitem. Reliabilitas skala kepuasan pernikahan ini adalah sebesar 0,881 .

$\begin{array}{llr}\text { Skala komunikasi interpersonal } \\ \text { disusun } & \text { berdasarkan } & \text { aspek-aspek }\end{array}$


komunikasi interpersonal yang dikemukakan oleh DeVito (2010) antara lain keterbukaan, empati, sikap mendukung, sikap positif, dan kesetaraan terdiri dari 15 aitem. Nilai reliabilitas skala komunikasi interpersonal ini adalah 0,830. Selanjutnya, kuisioner partner phubbing diadaptasi dari Partner Phubbing Scale oleh Roberts dan David (2016) terdiri dari sembilan aitem dengan lima alternatif jawaban yakni tidak pernah, jarang, kadang-kadang, sering, dan selalu dengan skor 1 sampai 5 dengan nilai reliabilitas sebesar 0,93 .

\section{Teknik Analisis Data}

Analisis data menggunakan bantuan software SPSS 16 for windows antara lain uji normalitas, uji linieritas, dan uji hipotesis.
Teknik yang digunakan dalam uji nomalitas adalah kolmogorov smirnov, uji linieritas menggunakan test for liniearity, dan uji hipotesis dengan simple regression.

\section{ANALISIS DAN HASIL}

Hasil uji normalitas pada tabel 1 menunjukkan bahwa nilai signifikansi sebesar 0,381 $(p>0,05)$ untuk variabel kepuasan pernikahan dan $0,454(p>0,05)$ untuk variabel komunikasi interpersonal artinya data dalam penelitian ini berdistribusi normal seperti yang terlihat pada tabel 1. Selanjutnya dari hasil uji liniearitas nilai signifikansi yang dihasilkan adalah $0,000(\mathrm{p}<0,05)$ yang berarti bahwa variabel-variabel dalam penelitian ini linier.

Tabel 1

Hasil Uji Normalitas

\begin{tabular}{cccc}
\hline Variabel & K-SZ & Sig & Keterangan \\
\hline $\begin{array}{c}\text { Kepuasan } \\
\text { Pernikahan }\end{array}$ & 0.909 & 0.381 & Normal \\
\hline $\begin{array}{c}\text { Komunikasi } \\
\text { Interpersonal }\end{array}$ & 0.857 & 0.454 & Normal \\
\hline
\end{tabular}

Kemudian hasil uji hipotesis yang telah dilakukan menunjukkan bahwa diperoleh nilai signifikansi sebesar 0,000 $(p<0,05)$ itu berarti hipotesis pada riset ini diterima yaitu ada peran komunikasi interpersonal terhadap kepuasan pernikahan pada partner phubbing. $R$-Square pada riset ini sebesar 0,434 itu berarti sumbangan efektif komunikasi interpersonal terhadap kepuasan pernikahan yakni sebesar $43,4 \%$ sisanya $56,6 \%$ kepuasan pernikahan dipengaruhi oleh faktor lain, seperti dapat terlihat pada tabel 2 . 
Tabel 2

Hasil Analisis Regresi

\begin{tabular}{llll}
\hline Variabel & $\mathrm{R}$ & $\begin{array}{l}R \text { - } \\
\text { Square }\end{array}$ & Sig \\
\hline $\begin{array}{l}\text { Kepuasan } \\
\text { Pernikahan- }\end{array}$ & 0,659 & 0,434 & 0.000 \\
$\begin{array}{l}\text { Komunikasi } \\
\text { Interepersonal }\end{array}$ & & & \\
\hline
\end{tabular}

Peneliti juga melakukan kategorisasi terhadap subjek penelitian. Pengkategorian dilakukan karena ingin menempatkan responden ke dalam kelompok dengan posisi yang berjenjang menurut suatu atribut yang diukur (Azwar, 2016). Maka dari itu, dalam penelitian ini peneliti membagi kategorisasi menjadi dua bagian yakni kategori tinggi dan rendah.

\begin{abstract}
Kategorisasi dalam variabel kepuasan pernikahan bisa dilihat dari skor median variabel kepuasan pernikahan. Hasilnya adalah 57. Berdasarkan data tersebut, dapat ditentukan kategorisasi untuk variabel kepuasan pernikahan sebagaimana ditampilkan pada tabel 3 .
\end{abstract}

Tabel 3

Kategorisasi Kepuasan Pernikahan Subjek Penelitian

\begin{tabular}{llll}
\hline Skor & Kategori & Frekuensi & Persentase \\
\hline $\mathrm{X}<63$ & Rendah & 114 & $49,6 \%$ \\
\hline $63 \leq \mathrm{X}$ & Tinggi & 116 & $50,4 \%$ \\
\hline Jumlah & & 230 & $100 \%$ \\
\hline
\end{tabular}

Dari analisis kategorisasi variabel kepuasan pernikahan tampak responden dengan kategori kepuasan rendah berjumlah 114 atau sebesar 49,6\% dan responden berada dalam kategori tinggi berjumlah 116 atau dengan persentasi 50,4\%.
Selanjutnya kategorisasi untuk variabel komunikasi interpersonal bisa dilihat dari skor median variabel kepuasan pernikahan. Hasilnya yakni 46. Berdasarkan data tersebut dapat ditentukan kategorisasi variabel komunikasi interpersonal sebagaimana terlihat pada tabel 4 .

Tabel 4

Kategorisasi Komunikasi Interpersonal Subjek Penelitian

\begin{tabular}{llll}
\hline Skor & Kategori & Frekuensi & Persentase \\
\hline $\mathrm{X}<51$ & Tidak efektif & 101 & $43,9 \%$ \\
\hline $51<\mathrm{X}$ & Efektif & 129 & $56,1 \%$ \\
\hline Jumlah & & 230 & $100 \%$ \\
\hline
\end{tabular}


Selain itu, peneliti juga melakukan analisis tambahan untuk melihat sumbangan efektif aspek-aspek komunikasi interpersonal untuk mengetahui aspek apa yang memiliki sumbangan efektif terbesar terhadap kepuasan pernikahan. Berdasarkan hasil perhitungan maka diperoleh hasil aspek yang memiliki sumbangan efektif terbesar adalah aspek kesetaraan yakni sebesar $15,419 \%$ seperti yang ditampilkan pada tabel 5 .

Tabel 5

Sumbangan Efektif Aspek-aspek Komunikasi Interpersonal

\begin{tabular}{cc}
\hline $\begin{array}{l}\text { Aspek-aspek Komunikasi } \\
\text { Interpersonal }\end{array}$ & Sumbangan Efektif \\
\hline Keterbukaan & $5,493 \%$ \\
\hline Empati & $6,757 \%$ \\
\hline Sikap mendukung & $15,259 \%$ \\
\hline Sikap positif & $2,478 \%$ \\
\hline Kesetaraan & $15,419 \%$ \\
\hline
\end{tabular}

\section{DISKUSI}

Hasil analisis data menunjukkan hipotesis dalam penelitian ini diterima. Terdapat beberapa penelitian terdahulu yang membahas tentang peran komunikasi interpersonal terhadap kepuasan pernikahan. Komunikasi yang efektif dengan pasangan dianggap menjadi salah satu faktor tercapainya kepuasan pernikahan (Jamhur \& Dwima, 2019). Kerukunan dalam menjalin pernikahan bergantung dengan keadaan interaksi satu sama lain yang efektif (Dewi \& Sudhana, 2013). Riset yang pernah dilakukan oleh Carrol (2012) menemukan bahwa diperlukan interaksi yang saling membangun dan menjauhi jenis interaksi yang dapat merusak serta menjadi pemicu konflik dikarenakan komunikasi yang baik bisa menciptakan rasa puas dalam pernikahan dan juga membantu dalam menangani konflik yang terjadi.

Hasil riset ini juga menunjukkan tidak ada efek negatif yang diberikan oleh fenomena partner phubbing untuk komunikasi interpersonal dan kepuasan pernikahan. Dapat diketahui dari kategorisasi komunikasi interpersonal efektif dengan besaram persentasi 50,5\% dan kategorisasi kepuasan pernikahan tinggi dengan besaran persentasi $51,5 \%$. Sejalan dengan riset yang dilakukan Borelli (2005) yang menemukan bahwa tidak ditemukan efek negatif pada penggunaan gadget dalam kepuasan pernikahan. Ada beberapa aspek yang mempengaruhi hasil riset tersebut di antaranya sampel yang kecil dan adanya faktor demografis. Penggunaan sampel yang lebih beragam dapat memungkinkan untu memberikan efek yang lebih luas. Responden yang berjumlah 230 orang mungkin menyebabkan data yang dihasilkan cukup minim.

Diindikasikan terdapat faktor-faktor lain yang mungkin berpengaruh adalah karena perilaku partner phubbing dianggap lumrah dan normal pada masa sekarang. Sesuai dengan riset Cizmeci (2017) yakni intensi untuk melihat bagaimana perbedaan persepsi partner phubbing dan kepuasan hubungan pada individu yang berpacaran dan individu yang sudah menikah di Turki, jumlah sampel sebanyak 500 responden untuk memperkirakan efek phubbing terhadap kepuasan hubungan di Turki. Dari riset ini ditemukan bahwa tidak ada efek negatif dari perilaku phubbing terhadap kepuasan hubungan pasangan di Turki.

Partner phubbing layaknya menjelma sebagai perilaku yang sulit dikendalikan, tidak terkecuali kepuasan 
hubungan seseorang. Di satu kondisi individu mengalami phubbing, namun di sisi yang lain individu tersebut adalah phubbers atau pelaku phubbing. Riset ini mengungkapkan bahwa phubbing adalah hal lumrah yang terjadi pada pasangan di Turki. Oleh sebab itu, penjelasan di atas juga bisa menjabarkan mengenai alasan mengapa responden dalam riset ini merasa puas dengan hubungan yang mereka jalani meskipun seiring dengan partner phubbing yang mereka alami (Cizmeci, 2017).

Riset ini juga selaras dengan riset Chotpitayasunondh dan Douglas (2016), yaitu pada saat individu menyaksikan tindakan phubbing kerap ditemui di dekat mereka dan banyak individu yang melakukannya, hingga individu-individu yang melihatnya menjadi berpikiran bahwa tindakan itu merupakan tindakan yang diterima di lingkungan sosial. Untuk memperkuat hasil riset, peneliti mencoba mewawancarai responden Y. Responden Y berjenis kelamin perempuan yang berada dalam kategori partner phubbing tinggi. Y berpendapat bahwa intensitas penggunaan gadget ketika berdua bukanlah pemantik utama munculnya masalah karena dianggap sebagai sesuatu yang normal. Bukan hanya pasangannya, $\mathrm{Y}$ sendiri kerap kali melakukan tindakan yang sama. $\mathrm{Y}$ mengutarakan jika kunci agar tidak ada masalah yang terjadi karena gadget adalah memaklumi satu sama lain.

Pandangan lainnya dikemukakan oleh Wang, Xie, Wang, Wang, dan Lei (2017) yang berpendapat ada dampak tidak langsung yang dihasilkan oleh partner phubbing sehingga dapat memicu adanya depresi melalui kepuasan pernikahan. Tetapi, semata-mata untuk pasangan yang sudah menikah dengan rentang lebih dari tujuh tahun saja. Di riset yang peneliti lakukan, responden dengan usia pernikahan tertinggi ada di rentang 0 sampai 3 tahun yaitu 91 responden $(45,5 \%)$. Peringkat selanjutnya di rentang usia pernikahan empat sampai tujuh tahun ialah 41 responden $(21 \%)$ sehingga terdapat kira-kira
$66,5 \%$ responden riset ini dalam rentang usia pernikahan di bawah tujuh tahun.

Selanjutnya, untuk uji hipotesis yang telah dilakukan diperoleh nilai $R$ square sebesar 0,450 atau sebesar $45 \%$ sehingga peranan komunikasi interpersonal terhadap kepuasan pernikahan adalah $45 \%$ sedangkan sisanya dipengaruhi oleh komponenkomponen lain. Berdasarkan riset Bradbury dkk. (2000), ketika mengarungi pernikahan ada elemen-elemen lain yang turut memberikan pengaruhnya misalnya latar belakang keluarga dan kepribadian pasangan. Elemen-elemen itulah yang ikut berpartisipasi dalam menciptakan atau mengubah perasaan puas sejalan dengan tahapan-tahapan yang telah dijalani dalam pernikahan.

Peristiwa-peristiwa dari masa lalu seseorang bisa berdampak baik ataupun buruk terhadap masa depan dan juga berdampak pada bagaimana seseorang menjalani kehidupannya khususnya pernikahan. Kepribadian seseorang juga lahir dari attachment dan interaksi dengan keluarga. Peneliti mencoba melakukan interview kepada responden RK (4 Juli 2020). RK adalah responden yang masuk dalam kategori kepuasan pernikahan rendah. Kesimpulan dari cerita RK adalah ada rasa tidak nyaman terhadap kepribadian yang dimiliki suaminya. RK merasa bahwa pasangannya memiliki ego yang tinggi dan suka menunda menyelesaikan masalah serta lebih memilih pergi meninggalkan rumah. Kerap kali karena watak suminya tersebut muncul masalah dalam keluarga mereka terlebih mustahil rasanya watak tersebut dapat dihilangkan.

RK menceritakan mengenai masa lalu suaminya yang dibesarkan oleh seorang ayah yang dominan dan bersikap cukup otoriter terhadap anak-anaknya. RK berasumsi bahwa mungkin hal tersebut menjadi salah satu watak yang terbawa sampai saat ini dalam diri suaminya. Perilaku suami RK yang kerap kali meninggakan rumah untuk menenangkan diri dan kembali ketika sudah dalam keadaan kepala dingin sudah tampak sejak mereka 
masih pacaran. Meski demikian, seiring berjalannya waktu hal tersebut kini sering terjadi dan RK memiliki kekhawatiran yang besar jika suatu saat perilaku tersebut bisa menciptakan masalah yang lebih besar. Wawancara ini menunjukkan kaitan elemenelemen lain yang dapat berpengaruh pada pernikahan seperti latar belakang kehidupan dan watak dari suami ataupun istri. Tetapi, dalam riset ini latar belakang kehidupan dan variabel kepribadian tidak diteliti.

Untuk mengetahui seberapa besar sumbangan efektif yang diberikan oleh aspek-aspek komunikasi interpersonal terhadap kepuasan pernikahan pada partner phubbing, maka peneliti melakukan analisis tambahan sehingga ditemukan bahwa sumbangan efektif tertinggi diberikan oleh aspek kesetaraan yaitu 15,96\%. Aspek kesetaraan didefinisikan sebagai aspek yang mengacu pada pengakuan kedua belah pihak bahwa mempunyai tujuan yang selaras, sama-sama bernilai, saling membutuhkan satu dan lainnya, dan kedudukan yang setara dengan pasangan. Carroll, Hill, Yorgason, Larson, dan Sandberg (2013) dalam risetnya menghasilkan bahwa komunikasi konstruktif seperti kebebasan berpendapat, tenang dalam menghadap permasalahan, metode penyampaian pesan jelas bisa berdampak baik pada hubungan keluarga dan kepuasan dalam rumah tangga.

Dalam penelitian ini topik mengenai partner phubbing adalah topik yang saat ini sering ditemui seiring dengan berkembangnya zaman dan teknologi. Kebiasaan menggunakan gadget ketika sedang berkumpul dengan orang-orang terdekat seperti menjadi kebiasaan baru yang juga dapat menyebabkan munculnya permasalahan baru. Meski demikian, di Indonesia sendiri penelitian terkait partner phubbing ataupun phubbing sendiri di Indonesia masih sangat minim sehingga referensi yang digunakan juga masih sangat terbatas. Selain itu, variabel-variabel yang berkaitan dengan partner phubbing beragam sehingga perlu diteliti lebih lanjut terkait dengan faktor atau variabel lain yang terjadi pada partner phubbing.

\section{SIMPULAN}

Dari riset yang telah dilakukan bisa ditarik kesimpulan bahwa ada peran komunikasi interpersonal terhadap kepuasan pernikahan pada partner phubbing, yang berarti hipotesis dalam penelitian ini diterima. Sumbangan efektif tertinggi diberikan oleh aspek kesetaraan dalam komunikasi interpersonal sehingga aspek tersebut memiliki pengaruh yang cukup tinggi dalam menciptakan kepuasan pernikahan pada partner phubbing.

\section{SARAN}

Berdasarkan temuan pada penelitian ini terlihat bahwa kontribusi yang diberikan terkait dengan literatur mengenai partner phubbing dalam konteks komunikasi interpersonal dan kepuasan pernikahan. Maka dari itu, diharapkan bagi individu yang telah menikah dan merupakan pengguna gadget sebaiknya terus meningkatkan komunikasi interpersonal yang efektif bersama pasangan, meningkatkan intensitas dan kualitas komunikasi satu sama lain serta saling terbuka. Seiring dengan perkembangan teknologi saat ini khususnya gadget, para pengguna diharapkan untuk mengoptimalkan penggunaan media-media komunikasi untuk hal-hal yang positif. Selain itu, masyarakat juga sebaiknya menggunakan gadget dengan bijaksana tanpa menganggu aktivitas sehari-hari dan berpikir kritis terkait resiko yang akan terjadi jika menggunakan gadget untuk halhal negatif ataupun berlebihan.

$$
\text { Adapun keterbatasan dalam }
$$
penelitian ini diantaranya adalah referensi terkait dengan fenomena partner phubbing yang masih minim. Kemudian dari penelitian ini juga dapat terlihat kemungkinan adanya variabel-variabel lain yang tidak diteliti. Fokus penelitian ini hanya sebatas melihat pengaruh fenomena partner phubbing terhadap komunikasi interpersonal dan kepuasan pernikahan bukan terkait dengan pola penggunaan gadget yang dapat meminimalisir efek buruknya. 
Diharapkan peneliti-peneliti selanjutnya dapat menggali lebih dalam mengenai fenomea partner phubbing karena di era globalisasi saat ini gadget seperti menjadi salah satu kebutuhan bagi setiap individu sehingga fenomena partner phubbing banyak ditemui. Penggunaan variabel-variabel yang terkait dengan fenomena partner phubbing juga perlu diteliti lebih jauh, misalnya melibatkan faktor kepribadian yang tidak diteliti dalam penelitian ini ataupun variabel lain yang memiliki keterkaitan dengan fenomena ini. Temuan yang berfokus pada cara meminimalisir dampak negatif dari penggunaan gadget tidak hanya pada pasangan namun dapat menjangkau subjek penelitian yang lebih luas dan bervariasi juga diperlukan karena di Indonesia sendiri masih sangat sedikit rujukan ataupun kepustakaan terdahulu yang mengambil topik mengenai partner phubbing.

\section{DAFTAR PUSTAKA}

Azwar, S. (2016). Penyusunan skala psikologi. Pustaka Pelajar.

Borrelli, J. (2015). Exploring the influence of smartphone technology within the context of marriage: an intervention study. Diakses dari http://ezproxy.lib.ryerson.ca/login?url= https://search.proquest.com/docview/16 91751698?accountid=13631\%0Ahttp:// sfx.scholarsportal.info/ryerson??url_ve $\mathrm{r}=\mathrm{Z39}$.88-

2004\&rft_val_fmt=info:ofi/fmt:kev:mt $\mathrm{x}$ :dissertation $\&$ genre $=$ dissertations $+\% 2$ 6+theses\&sid=ProQ:ProQ

Bradbury, T. N., Fincham, F. D., \& Beach, S. R. H. (2000). Research on the nature and determinants of marital satisfaction: A decade in review. Journal of Marriage and Family, 62(4), 964-980. doi $10.1111 / \mathrm{j} .1741$ 3737.2000.00964.x.

Carandang, M. N. S., \& Guda, I. V. P. (2015). Indicators of marital satisfaction of Batangueño couples: Components of love and the other external factors in marriage. International Journal of Information and Education Technology, 5(1), 60-67. doi

0.7763/ijiet.2015.v5.477.

Carroll, S. (2012). Couple communication as a mediator between work-family conflict and marital satisfaction. Contemporary Family Therapy, 35(3), 530-545. doi:10.100710591-013-92377.

Cizmeci, E. (2017). Disconnected, though satisfied: pphubbing behavior and relationship satisfaction. The Turkish Online Journal of Design, Art and Communication, 7(2), 364-375.

Chotpitayasunondh, V., \& Douglas, K. M. (2016). How "phubbing" becomes the norm: The antecedents and consequences of snubbing via smartphone. Computers in Human Behavior, 63, 9-18. doi:10.1016/j.chb.2016.05.018.

Chotpitayasunondh, V., \& Douglas, K. M. (2018). The effects of "phubbing" on social interaction. Journal of Applied Social Psychology, 48(6), 304-316. doi:10.1111/jasp.12506.

DeVito, A. J. (2010). Komunikasi antarmanusia $\quad\left(5^{\text {th }}\right.$ Ed.). Karisma Publishing.

Dewi, N. R., \& Sudhana, H. (2013). Hubungan antara komunikasi interpersonal pasutri dengan keharmonisan dalam pernikahan. Jurnal Psikologi Udayana, 1(1), 22-30. doi :10.24843/jpu.2013.v01.i01.p03.

Iqbal, M. (2018). Psikologi pernikahan: Menyelami rahasia pernikahan. Gema Insani.

Jamhur, M., \& Dwima, A. (2019). Pengaruh komunikasi efektif terhadap kepuasan pernikahan pada pasangan yang melakukan pernikahan dini. Cognicia, 7(4), 475-491.

Lavner, J. A., Karney, B. R., \& Bradbury, T. N. (2016). Does couples' 
communication predict marital satisfaction, or does marital satisfaction predict communication?. Journal of Marriage and Family, 78(3), 680694. doi:10.1111/jomf.12301.

Litzinger, S., \& Gordon, K.C. (2005). Exploring relationships among communication, sexual satisfaction, and marital satisfaction. Journal of Sex \& Marital Therapy, 31(5), 409-424. doi: 10.1080/00926230591006719.

Marpaung, J. (2018). Pengaruh penggunaan gadget dalam kehidupan. Kopasta: Jurnal Program Studi Bimbingan Konseling, 5(2), 55-64. doi: 10.33373/kop.v5i2.1521.

McDaniel, B. T., \& Coyne, S. M. (2016). "Technoference": The interference of technology in couple relationships and implications for women's personal and relational well-being. Psychology of Popular Media Culture, 5(1), 85-98. doi :10.1037/ppm0000065.

Muslimah. (2014). Kepuasan pernikahan ditinjau dari keterampilan komunikasi interpersonal. Jurnal Soul, 7(2), 15-22.

Ngafifi, M. (2014). Kemajuan teknologi dan pola hidup manusia dalam perspektif sosial budaya. Jurnal Pembangunan Pendidikan: Fondasi Dan Aplikasi, 2(1), 33-47. doi : 10.21831/jppfa.v2i1.2616.

Papalia, D. E., Olds, S. W., \& Feldman, R. D. (2009). Human development: Perkembangan manusia. Salemba Humanika.

Roberts, J. A., \& David, M. E. (2016). My life has become a major distraction from my cell phone: Partner phubbing and relationship satisfaction among romantic partners. Computers in Human Behavior, 54, 134-141. doi :10.1016/j.chb.2015.07.058.

Srisusanti, S., \& Zulkaida, A. (2013). Studi deskriptif mengenai faktor-faktor yang mempengaruhi kepuasan perkawinan pada istri. UG Jurnal, 1(1), 133-141. doi.org/10.13140/RG.2.2.30630.32324.

Tavakolizadeh, J., Nejatian, M., \& Soori, A. (2015a). The effectiveness of communication skills training on marital conflicts and its different aspects in women. Procedia - Social and Behavioral Sciences, 171, 214-221. doi :10.1016/j.sbspro.2015.01.112.

Wang, X., Xie, X., Wang, Y., Wang, P., \& Lei, L. (2017). Partner phubbing and depression among married Chinese adults: The roles of relationship satisfaction and relationship length. Personality and Individual Differences, 110, 12-17.

Wang, X., Zhao, F., \& Lei, L. (2019). Partner phubbing and relationship satisfaction: Self-esteem and marital status as moderators. Current Psychology. doi:10.1007/s12144-01900275-0.

Youarti, I. E., \& Hidayah, N. (2018). Perilaku phubbing sebagai karakter remaja generasi z. Jurnal Fokus Konseling, 4(1), 143-152. doi :10.26638/jfk.553.2099. 